\title{
Changes of the Electrode Surface Roughness Induced by High-Voltage Electric Pulses as Revealed by AFM
}

\author{
R. Rodaitė-RiŠEviČIEnE $\dot{E}^{a, b}$, G. SAUlis ${ }^{a, *}$ AND V. SNitkA ${ }^{b}$ \\ ${ }^{a}$ Vytautas Magnus University, 58 K. Donelaičio str., LT-44248 Kaunas, Lithuania \\ ${ }^{b}$ Kaunas University of Technology, 65 Studentug str., LT-51369 Kaunas, Lithuania
}

\begin{abstract}
The changes of the surface topography of stainless-steel and aluminium electrodes occurring due to the action of electric pulses which are utilized for cell electroporation, have been studied by using atomic force microscopy. The surfaces of the polished stainless-steel electrodes were smooth - the average roughness was 13-17 $\mathrm{nm}$ and the total roughness $140-180 \mathrm{~nm}$. The total roughness of the aluminium electrodes was about $320 \mathrm{~nm}$. After the treatment of the chambers filled with $154 \mathrm{mM} \mathrm{NaCl}$ solution by a series of short $(20-40 \mu \mathrm{s})$, high-voltage $(4 \mathrm{kV})$ pulses with the total dissolution charge of $0.20-0.26 \mathrm{~A} \mathrm{~s} / \mathrm{cm}^{2}$, the roughness of the surface of the electrodes has increased, depending on the total amount of the electric charge that has passed through the unit area of the electrode. Up to a two- and threefold increase of the surface roughness of the stainless-steel and aluminium anodes respectively was observed due to the dissolution of the anode material. Therefore, the use of high-voltage electric pulses leads to the increase of the inhomogeneity of the electric field at the electrode, which facilitates the occurrence of the electric breakdown of the liquid samples and causes non-equal treatment of each cell.
\end{abstract}

PACS numbers: 87.80.-y, 82.45Fk, 68.37.Ps

\section{Introduction}

Cell electroporation - a temporal increase of cell membrane permeability due to the action of pulses of strong electric field (up to $300 \mathrm{kV} / \mathrm{cm}$ ) — is widely used in cell biology, biotechnology and medicine [1]. However, when a high voltage is applied to the electrolyte solution, besides a cell membrane permeabilization, a variety of electrolysis reactions occur at the electrodesolution interfaces [2]. These reactions cause changes of the chemical composition $[3,4]$ or $\mathrm{pH}[5]$ of the experimental medium. When a non-inert anode is utilized, the dissolution of the anode material occurs due to the oxidation of the metal of the electrode [2]. The metal ions released from the electrodes might affect some physiological processes [3].

Atomic force microscopy (AFM) is a recently developed scanning probe microscopy that allows obtaining precise three-dimensional topography of the object surface and geometrical parameters of the elements with a subnanometer resolution [6]. By using AFM, we have recently demonstrated that the roughness of the stainless-steel anode surface increased due to its dissolution occurring under the action of high-voltage electric pulses commonly utilized for cell electroporation [7].

For many applications of cell electroporation, it is necessary to apply the pulses of as homogeneous electric field

* corresponding author; e-mail: g.saulis@gmf.vdu.lt as possible [8]. Meanwhile, the rough electrode surface creates local enhancements of the electric field, which lead to the inhomogeneity of an electric treatment of each cell and can facilitate the occurrence of the electrical breakdown of the liquid samples [7].

One of the most popular electrode materials used in commercially available cuvettes is aluminum [3, 9]. Here, the changes of the topography of the aluminium and stainless-steel anode surface, occurring under similar conditions, were compared using the same approach.

\section{Experimental}

Commercially available cuvettes with aluminium electrodes (inter-electrode distance $-2 \mathrm{~mm}$, chamber volume - $1 \mathrm{ml}$, CUV-02, Cyto Pulse Sciences, Inc., Columbia, MD, USA) and a home made cuvette with stainless steel (AISI 304, GOST $08 \times 18 \mathrm{H} 10$ ) electrodes (inter-electrode distance $-1 \mathrm{~cm}$, chamber volume $2 \mathrm{ml}$ ) were studied. The dissolution of the electrodes was obtained by discharging several times a high-voltage $1 \mu \mathrm{F}$ capacitor (charged to $4 \mathrm{kV}$ ) through the chamber filled with a $154 \mathrm{mM} \mathrm{NaCl}$ solution the specific conductivity of which was about $1.6 \mathrm{~S} / \mathrm{m}$. The interval between electric pulses was kept within the range of 2-3 minutes to avoid any thermal effects.

Three-dimensional surface topography of the electrodes was studied with atomic force microscope Quesant Qscope-250 (Ambios Technology Company, Santa Cruz, CA, USA). The data were acquired in the contact mode of AFM with silicon cantilevers. The lever parameters 
of the microfabricated V-shaped silicon cantilevers were: length $200 \mu \mathrm{m}$, width $40 \mu \mathrm{m}$, thickness $1 \mu \mathrm{m}$, resonant frequency $32 \mathrm{kHz}$, force constant $0.35 \mathrm{~N} / \mathrm{m}$, and tip curvature radius $10 \mathrm{~nm}$. A set of frames of the same size $\left(30 \times 30 \mu \mathrm{m}^{2}\right)$ was taken from different areas of the sample surface. All measurements were done in ambient environment at the room temperature. AFM images were processed with software SPIP v. 2.3206 (Image Metrology A/S, Lyngby, Denmark) [7].

\section{Results and discussion}

We have studied the changes of the topography of stainless-steel and aluminium anodes, occurring under the action of high-voltage electric pulses commonly utilized for cell electroporation. At first, the surfaces of the polished stainless-steel and intact aluminium electrodes prior to the electric treatment were investigated by using atomic force microscopy. Figure $1 \mathrm{~A}$ shows a typical three-dimensional image of the surface of the freshly polished stainless-steel electrode. The scanning area was $30 \times 30 \mu \mathrm{m}^{2}$. The height profile of the electrode surface along the white line is shown in Fig. 2A. It can be seen from this figure that the surface is rather smooth - the average roughness, $R_{a}$, calculated for the electrode surface three-dimensional image shown in Fig. 1A was $13-17 \mathrm{~nm}$ and the total roughness (the vertical distance from the deepest valley to the highest peak), $R_{t}$, was $154 \mathrm{~nm}$. Long straight narrow $(\approx 1 \mu \mathrm{m})$ not deep $(10-50 \mathrm{~nm})$ scratches seen on the electrode surface are most likely a result of the mechanical polishing process. Although the surface of the untreated aluminium electrode was not smooth - the total roughness of the surface, $R_{t}$, was about $350 \mathrm{~nm}$ and the average roughness was $25-35 \mathrm{~nm}$ (Fig. 3A) - no sharp peaks were observed on the surface. The height profile of the electrode surface is shown in Fig. $4 \mathrm{~A}$.

Then, the chambers filled with $154 \mathrm{mM} \mathrm{NaCl}$ solution were exposed to a series of short $(20-40 \mu \mathrm{s})$, high-voltage $(4 \mathrm{kV})$ pulses. To avoid any thermal effects, the interval between electric pulses was kept within the range of 2-3 minutes. After the treatment, the roughness of the surfaces of the anodes has increased due to the dissolution of the electrode material (mainly $\mathrm{Fe}^{2+} / \mathrm{Fe}^{3+}$ and $\mathrm{Al}^{3+}$ ). The character and extent of the changes were dependent on the anode material and the total amount of the electric charge that has passed through the unit area of the electrode.

A three-dimensional image of Fig. 1B provides quantitative information on the stainless-steel anode surface topography after the exposure to a series of 100 exponential electric pulses giving the total dissolution charge $Q_{\text {dis }}=0.20 \mathrm{~A} \mathrm{~s} / \mathrm{cm}^{2}$. The height profile of the anode along the white line shown in Fig. 1B is presented in Fig. 2B. As in the previous case, the scanning area was $30 \times 30 \mu \mathrm{m}^{2}$. It can be seen that the surface of the stainless-steel anode has become much rougher. The total roughness, $R_{a}$, exceeded $300 \mathrm{~nm}$ (increased about
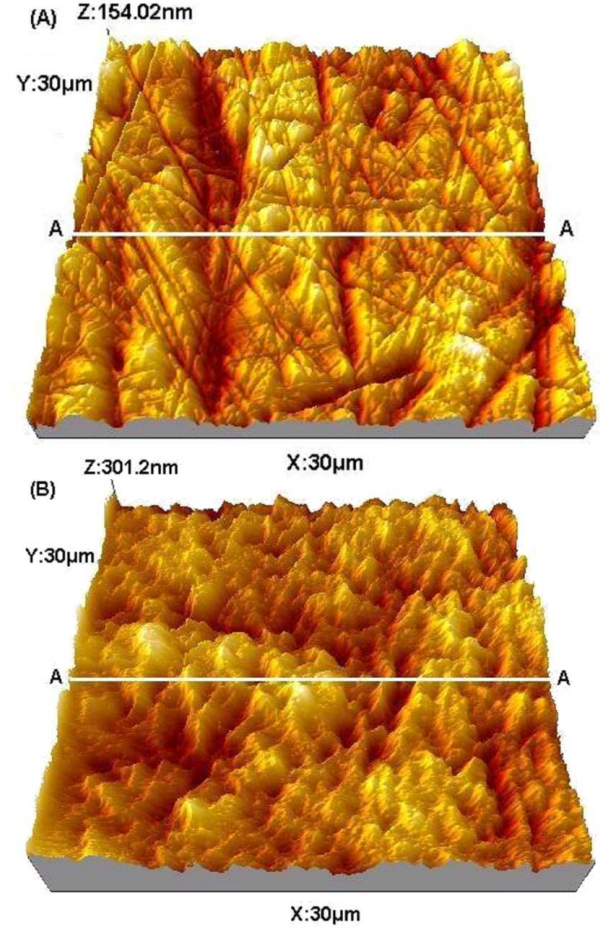

Fig. 1. AFM three-dimensional images of the stainless-steel anode surface: (A) prior to the exposure by high-voltage $(4 \mathrm{kV})$ electric pulses and (B) after the exposure to 100 exponential pulses with the duration of about $20 \mu$ s and dissolution charge $Q_{\text {diss }}=0.20 \mathrm{~A} \mathrm{~s} / \mathrm{cm}^{2}$. Scanning area $30 \times 30 \mu \mathrm{m}^{2} ; z$ range: (A) $154.02 \mathrm{~nm}$, (B) $301.2 \mathrm{~nm}$.

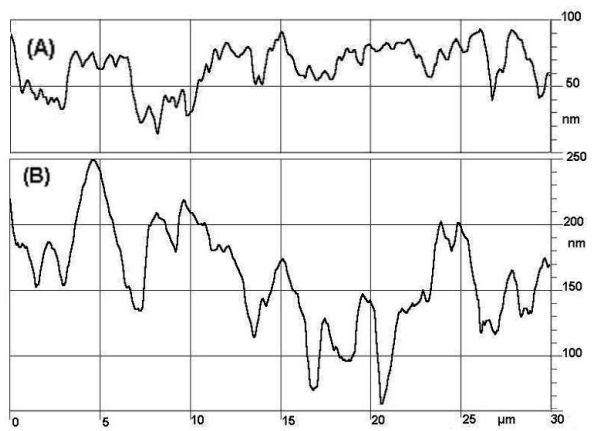

Fig. 2. Cross-sections of the stainless-steel anode surface (height profiles) along white lines A in Fig. 1: (A) prior to the exposure by high-voltage $(4 \mathrm{kV})$ electric pulses and (B) after the exposure to 100 exponential pulses with the duration of about $20 \mu$ s (dissolution charge $\left.Q_{\text {diss }}=0.20 \mathrm{~A} \mathrm{~s} / \mathrm{cm}^{2}\right)$.

twice). None changes of the stainless-steel cathode surface were detected [7].

After the treatment by 90 short exponential (time constant of about $40 \mu \mathrm{s})$ high-voltage $(4 \mathrm{kV})$ electric pulses, surface topography of the aluminium anode has changed remarkably (Fig. 3B). The total roughness exceeded $0.94 \mu \mathrm{m}$ for the dissolution charge of $0.26 \mathrm{~A} \mathrm{~s} / \mathrm{cm}^{2}$. So, 

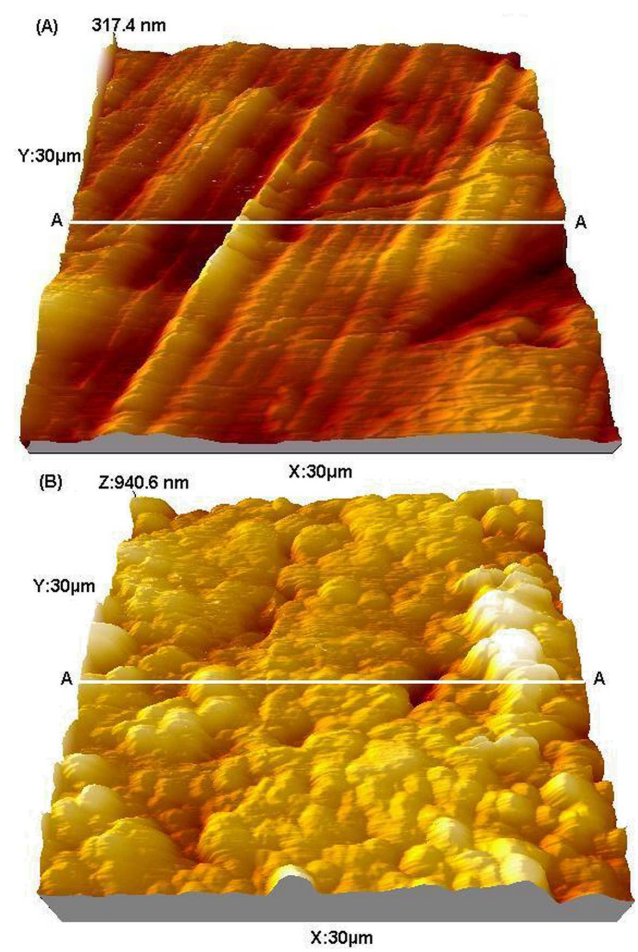

Fig. 3. AFM three-dimensional images of the aluminium anode surface: (A) prior to the exposure by high-voltage $(4 \mathrm{kV})$ electric pulses and (B) after the exposure to 90 exponential pulses with the duration of about $40 \mu \mathrm{s}$ (dissolution charge $Q_{\text {diss }}=0.26 \mathrm{~A} \mathrm{~s} / \mathrm{cm}^{2}$ ). Scanning area $30 \times 30 \mu \mathrm{m}^{2}$; $z$ range: (A) $317.4 \mathrm{~nm}$, (B) $940.6 \mathrm{~nm}$.

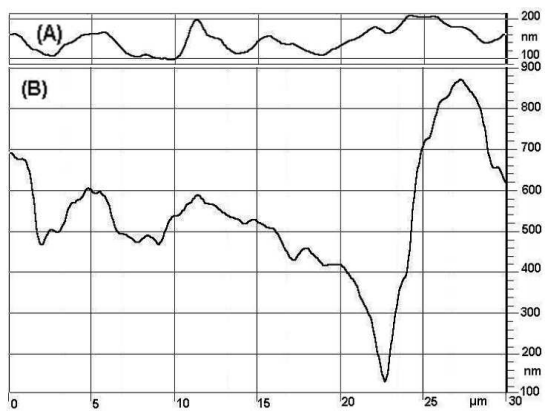

Fig. 4. Cross-sections of the aluminium anode surface (height profiles) along white lines A in Fig. 1: (A) prior to the exposure by high-voltage $(4 \mathrm{kV})$ electric pulses and (B) after the exposure to 90 exponential pulses with the duration of about $40 \mu \mathrm{s}$ (dissolution charge $Q_{\text {diss }}=$ $\left.0.26 \mathrm{~A} \mathrm{~s} / \mathrm{cm}^{2}\right)$.

the total roughness of the anode has increased about 3 times (Fig. 4B). In addition, the character of the topography of aluminium anode surface was altered too - it consisted of small 2-3 $\mu \mathrm{m}$-size grains (Fig. 3B). After the treatment, the changes of the aluminium cathode surface have also been observed (data not shown).
The AFM images showed the changes of the topography of stainless-steel and aluminium anodes due to release of metal ions (mainly $\mathrm{Fe}^{2+} / \mathrm{Fe}^{3+}$ and $\mathrm{Al}^{3+}$ ) from them as a result of the oxidation of the metal. The authors hope that the approach for studying the changes of the surface topography by using AFM, utilized here and the results obtained can be helpful in finding the solutions for increasing the longevity of the electrodes as well as avoiding the problems arising due to the anodic half-reactions and contamination of the solution by the release of metal ions from the electrodes.

\section{Conclusions}

It can be concluded that the changes of the surface roughness of stainless-steel and aluminium anodes occur due to the action of electric pulses which are commonly utilized in cell electroporation procedures. The character and extent of these changes depend on the anode material and the total amount of the electric charge that has passed through the unit area of the electrode. Up to a two- and threefold increase of the surface roughness of the stainless-steel and aluminium anodes respectively has been observed. Increased roughness creates local enhancements of the electric field at the interface between the solution and the electrode surface and can facilitate the occurrence of the electric breakdown of the liquid samples as well as cause non-equal treatment of each cell.

\section{Acknowledgments}

This work was in part supported by grant C-03046 from the Lithuanian State Science and Studies Foundation.

\section{References}

[1] J. Gehl, Acta Physiol. Scand. 177, 437 (2003).

[2] G. Milazzo, Electrochemistry: Theoretical Principles and Practical Applications, Elsevier, Amsterdam 1963.

[3] J.W. Loomis-Husselbee, P.J. Cullen, R.F. Irvine, A.P. Dawson, Biochem. J. 277, 883 (1991).

[4] T. Tomov, I. Tsoneva, Bioelectrochemistry 51, 207 (2000).

[5] G. Saulis, R. Lape, R. Praneviciute, D. Mickevicius, Bioelectrochemistry 67, 101 (2005).

[6] G. Binnig, C.F. Quate, C. Gerber, Phys. Rev. Lett. 56, 930 (1986).

[7] G. Saulis, R. Rodaite-Riseviciene, V. Snitka, Bioelectrochemistry 70, 519 (2007).

[8] I.E. Pol, W.G.C. van Arendonk, H.C. Mastwijk, J. Krommer, E.J. Smid, R. Moezelaar, Appl. Environ. Microbiol. 67, 1693 (2001).

[9] M. Puc, S. Čorovic, K. Flisar, M. Petkovšek, J. Nastran, D. Miklavčič, Bioelectrochemistry 64, 113 (2004). 